\title{
Hyaluronic Acid act as a Non - Invasive Marker for Diagnosis of Liver Fibrosis in the Patients of Chronic Hepatitis C
}

\author{
Muhammad Akram, Ali Raza Memon, Pushpa, Farman Ullah Farman, \\ Muhammad Imtiaz Shafiq
}

\section{ABSTRACT}

OBJECTIVE: To evaluate the biochemical significance of Hyaluronic acid in liver fibrosis among chronic hepatitis $C$ patients to eliminate repetitive liver biopsies.

METHODOLOGY: Cross Sectional Comparative Analytical Study at FPGMI, Shaikh Zayed Hospital, Lahore from January 2017 to December 2017. This cross-sectional study, included patients of chronic hepatitis $C(n=250)$ along with controls $(n=100)$. Serum hyaluronic acid assay (patients $\&$ controls) was performed using enzyme linked binding protein assay, using a capture molecule known as hyaluronic acid binding protein (HABP) along with quantitative Echelon (Echelon biosciences Inc. USA) used as reference standard.

RESULTS: Total 350 participant both male and females participated for this study from these 350 samples, 100 normal samples were recruited as control group and 250 diagnosed cases of chronic hepatitis $C$ patients were recruited as case study group. Serum Hyaluronic acid was significantly $(P<0.001)$ elevated in patients $(195.77 \pm 6.67)$ compared to controls $(110.2 \pm 0.79)$ irrespective of gender involvement.

CONCLUSION: The current findings showed significant involvement of HA in early prognosis of liver fibrosis and cirrhosis among chronic HCV patients that would probably useful to reduce repetitive liver biopsy.

KEY WORDS: Hyaluronic acid, Liver fibrosis, Hepatitis C

This article may be cited as: Akram M, Memon AR' Pushpa, Ullah Farman F, Shafiq MI. Hyaluronic Acid act as a Non - Invasive Marker for Diagnosis of Liver Fibrosis in the Patients of Chronic Hepatitis C. J Liaquat Uni Med Health Sci. 2018;17(03):161-4. doi: $10.22442 /$ jumhs. 181730570

\section{INTRODUCTION}

Hepatitis $\mathrm{C}$ is a global health problem affected significant portion of the world's population. It is estimated that 170 million active hepatitis $C$ carriers are present worldwide, while 3-4 million new cases are register each year ${ }^{1}$ and $85 \%$ among them progress to chronic liver disease ${ }^{2}$. Chronic hepatitis C virus infection is a progressive disease that is often associated with the development of hepatocellular carcinoma, liver cirrhosis as well as liver failure and eventually death ${ }^{3}$. Moreover, hepatitis $C$ infection play crucial role to induce liver fibrosis due to imbalance between hepatic decomposition and removal of extra cellular matrix (ECM) by myo-fibroblast that often threaten to develop liver cirrhosis ${ }^{4}$. Hepatic stellate cells (HSCs) are major fibrogenic cells of liver that control both synthesis and degradation of $\mathrm{ECM}^{5}$. HCV -induced activation and proliferation of HSCs is often associated with enhanced production of various cytokines (TGF-a \&TGF- $\beta 1$ ) that are crucial to induce ECM production and to progress liver fibrosis ${ }^{4}$. It has been found that fibrotic liver showed 6 fold increase in ECM compare to normal liver ${ }^{6}$. Therefore, an affective measurement of liver fibrosis has been found critical in early diagnosis prior to develop cirrhosis that not only improve survival but can significantly reduce the need for liver transplantation?.

Various invasive and non-invasive markers have been assessed in early prognosis to predict liver fibrosis. Among the most common invasive procedures, liver biopsy is most well-known and gold standard procedure to monitor histology as well as progression to chronic stage ${ }^{8}$. However, liver biopsy does not reflect the complete picture of fibrotic liver, nevertheless to show only $1 / 50000$ volume per single biopsy that contain 5-11 complete portal tract. Similarly various other drawbacks such risk of severe 
hemorrhage due to injury of hepatic and biliary system as well as consent of refusing liver biopsy from large portion of patients, ultimately reduce the significance of liver biopsy in the prognosis of liver fibrosis. Furthermore liver biopsy also failed to monitor, stage wise progression of fibrotic liver ${ }^{8}$, So now serum hyaluronic acid levels also helpful the diagnosis and staging of liver fibrosis in patients of chronic hepatitis $\mathrm{C}$.

\section{METHODOLOGY}

Cross Sectional Comparative Analytical Study conducted in Federal Postgraduate Medical Institute, Shaikh Zayed Hospital Lahore-Pakistan from January 2017 to December 2017. Sample size was 250 patients and 100 healthy subjects (Controls).

Inclusion Criteria: The total 250 patients (179 males and 71 females) with chronic hepatitis C (ELISA ${ }^{\text {+ve }}$, $\mathrm{qPCR}^{\text {+ve }}$ positive) were recruited having ages of 3060 years along with 100 healthy subjects (controls) from both age/sex matched individuals. Exclusion Criteria: Patients of chronic liver disease having acute hemolysis, history of bleeding diathesis, alcoholic liver cirrhosis, extra hepatic cholestasis as well as hepatitis $C$ patients which have been treated with interferon alpha or ribavirin were excluded.

Blood $(5 \mathrm{~mL})$ was collected from both patients and controls in vacutainers having clot activator. Serum was separated by centrifugation using auto-pipette and was preserved at $-80^{\circ} \mathrm{C}$ in sterilized eppendorff tube for further detail analysis.

Serum hyaluronic acid assay (patients \& controls) was performed using enzyme linked binding protein assay, using a capture molecule known as hyaluronic acid binding protein (HABP) along with quantitative Echelon (Echelon biosciences Inc. USA) used as reference standard ${ }^{9}$.

\section{Statistical analysis:}

The Data was statistically analyzed by SPSS 16 by applying ANOVA test. The $p$ value $<0.05$ were considered as statistically significant.

\section{RESULTS}

Hyaluronic acid was significantly elevated in sera of hepatitis $C$ infected individuals. Hyaluronic acid is investigated as a signature for liver fibrosis among hepatitis C infected individuals in the current cross-sectional analysis. Hyaluronic acid level in sera of hepatitis $C$ infected individuals was found higher with relatively two-fold increment $(195.77 \pm 6.67)$, relative to the control group $(110.2 \pm 0.79)$ of the study cohort (Table I). Interest- ingly, the degree of elevation was found statistically significant $(P<0.001)$ among control and diseased subjects. Moreover, to evaluate the gender specific declamation, the study was elaborated to calculate the serological peak of hyaluronic acid among male and female individuals of the cohort. However, no pronounced effect of hyaluronic acid level was found between male and female individuals, rather to showed strong significant $(P<0.001)$ elevation of hyaluronic acid among control and diseased specimens, irrespective of gender (Table II \& Graph II). These findings were very logical to acknowledge that hyaluronic acid might be a gender independent factor to calculate the severity of liver fibrosis in chronic hepatitis $C$ patients.

\section{TABLE I:}

COMPARISON OF SERUM HYALURONIC ACID IN CONTROL \& CASE STUDY GROUP

\begin{tabular}{|c|c|}
\hline Group & $\begin{array}{c}\text { Serum Hyaluronic Acid } \\
\text { (ng/ml) }\end{array}$ \\
\hline Control & $110.2 \pm 0.79$ \\
\hline Case Study Group & $195.77 \pm 6.67^{* *}$ \\
\hline
\end{tabular}

$\left({ }^{* *}=p<0.001\right)$

TABLE II:

COMPARISON OF PEAK SERUM HYALURONIC ACID LEVEL BETWEEN MALES \& FEMALES

\begin{tabular}{|c|c|}
\hline Gender & $\begin{array}{c}\text { Peak Serum Hyaluronic } \\
\text { Acid }(\mathrm{ng} / \mathrm{ml}){ }^{* *}\end{array}$ \\
\hline Male $(n=179)$ & $198.24 \pm 3.37$ \\
\hline Female $(n=71)$ & $196.11 \pm 4.59$ \\
\hline$\left.{ }^{* *}=p<0.001\right)$ &
\end{tabular}

\section{GRAPH I:}

\section{Serum Hyaluronic Acid (ng/ml)}

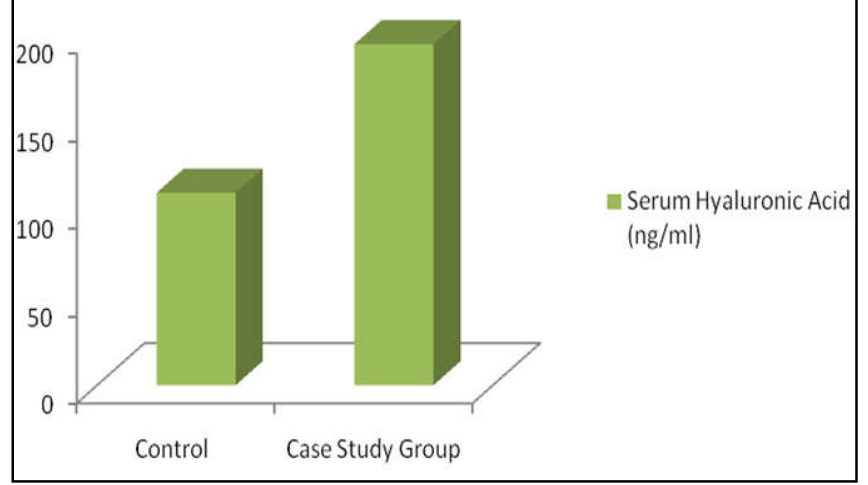




\section{GRAPH II:}

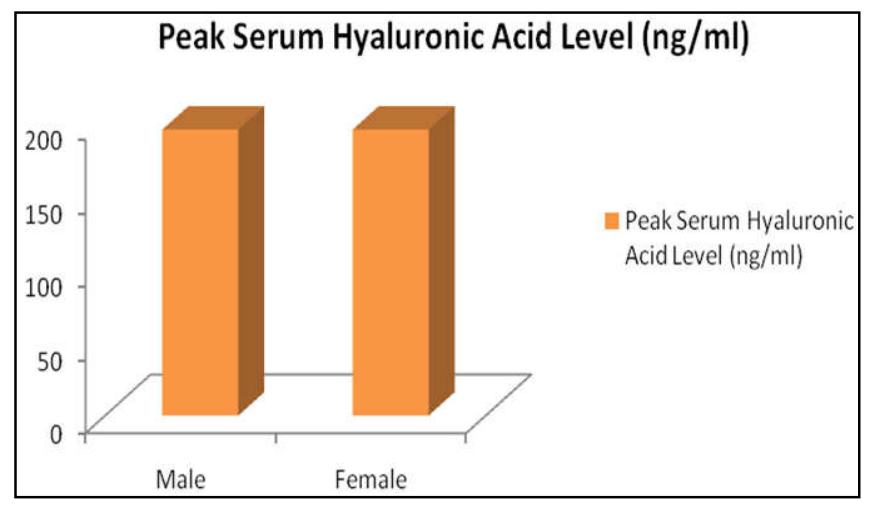

\section{DISCUSSION}

Hepatitis $C$ is a progressive disease that play crucial role in liver fibrosis as well as cirrhosis that finally develop hepatocellular carcinoma. The prognostic measurement of liver fibrosis is very essential to assess liver damage. Histological examination of liver biopsy is currently available gold standard procedure for assessing liver lesions, however due to invasive nature and severe complications; the technique is generally avoided ${ }^{10}$. Moreover, liver biopsy also full of ethical intervention that cannot be advised to monitor liver status repeatedly ${ }^{11}$. The findings of these trials are also particularly useful to develop fibrotic marker; hence investigators can choose an assay suitable for routine patient monitoring.

In current study, serum hyaluronic acid is extensively evaluated as a non-invasive marker among clinically diagnosed chronic hepatitis $C$ patients. Hyaluronic acid (HA) is an anionic, non sulfated glycosaminogly can distributed widely throughout connective, epithelial, and neural tissues ${ }^{12,13}$. Both metabolic activities and serum concentration of $\mathrm{HA}$ are precisely regulated by hepatic sinusoids ${ }^{14}$. Various study suggested that HA contributes significantly in cell proliferation and migration that could be involved in the progression of some malignant tumors ${ }^{14}$. Moreover, its concentration in normal liver is found lower compared to fibrotic liver, showed both relative and absolute increase of hyaluronic acid ${ }^{15}$.

Our results showed significant $(P<0.001)$ increase of hyaluronic acid concentration in serum of chronic hepatitis $C$ patients (mean $=195.77 \pm 6.67$ ) compared to the normal (mean $=110.2 \pm 0.79$ ) individuals. Similarly, higher HA level was also found among males and female individuals of the cohort. The cutoff value obtained to differentiate fibrotic (diseased), from non-fibrotic individuals was $>150 \mathrm{ng} / \mathrm{l}$. Our findings are in accordance with some previous preliminary findings that also showed elevated serum HA level with a cutoff of value of $181.98 \mathrm{ng} / \mathrm{ml}^{15}$ as well as $167.98 \mathrm{ng} /$ $\mathrm{ml}^{16}$ among chronic hepatitis $\mathrm{C}$ patients ${ }^{17}$. Obviously, the constant increase of $\mathrm{HA}$ level suggesting uniform role of $\mathrm{HA}$, irrespective of gender specific classification among these studied individuals. Interestingly, patients possessed advanced level of liver fibrosis (F4) had higher HA level than patients with initial stage of liver fibrosis among our study cohort. Similar finding had been reported that HA level is a precise predictor of liver fibrosis among hepatitis B infected individuals that was significantly correlated with various stages ${ }^{18}$.

Therefore, these findings provided better clue for the involvement of HA in liver fibrosis among chronic hepatitis C patients. Therefore, these extensive findings of $\mathrm{HA}$ might be an agreement to have a significant role in early prediction of liver fibrosis as well as in routine diagnosis of liver diseases, especially when liver biopsy is contraindicated. However further study is needed on a large group of patients, to investigated and validate the findings regarding $\mathrm{HA}$ level in normal and diseased individuals as well as study at various stages of liver fibrosis.

\section{Conflict of interest}

The work presented for this publication is solely non-profit and all authors committed to have no competitive interests during and after the journal production.

\section{REFERENCES}

1. Petruzziello A, Marigliano $S$, Loquercio $G$, Cozzolino A, Cacciapuoti C. Global epidemiology of hepatitis $C$ virus infection: An up-date of the distribution and circulation of hepatitis $C$ virus genotypes. World J Gastroenterol. 2016; 22 (34): 7824-40.

2. Mohd Hanafiah K, Groeger J, Flaxman AD, Wiersma ST. Global epidemiology of hepatitis C virus infection: new estimates of age-specific antibody to HCV seroprevalence. Hepatology. 2013; 57 (4): 1333-42.

3. Singer AW, Reddy KR, Telep LE, Osinusi AO, Brainard DM, Buti $M$, et al. Direct-acting antiviral treatment for hepatitis $C$ virus infection and risk of incident liver cancer: a retrospective cohort study. Aliment Pharmacol Ther. 2018; 47(9): 1278-87.

4. Aoudjehane L, Bisch G, Scatton O, Granier C, Gaston J, Housset C, et al. Infection of Human Liver Myofibroblasts by Hepatitis C Virus: A Direct Mechanism of Liver Fibrosis in Hepatitis C. PLoS One. 2015; 10 (7): e0134141.

5. Pasarín M, Abraldes JG, Liguori E, Kok B, La Mura V. Intrahepatic vascular changes in non-alcoholic fatty liver disease: Potential role of insulin-resistance and endothelial dysfunction. World J Gastroenterol. 2017; 23(37): 6777-87. 
6. Szabo G, Momen-Heravi F. Extracellular vesicles in liver disease and potential as biomarkers and therapeutic targets. Nat Rev Gastroenterol Hepatol. 2017; 14(8): 455-466.

7. Crossan C, Tsochatzis EA, Longworth L, Gurusamy K, Papastergiou V, Thalassinos E, et al. Cost-effectiveness of noninvasive liver fibrosis tests for treatment decisions in patients with chronic hepatitis B in the UK: systematic review and economic evaluation. J Viral Hepat. 2016; 23(2): 139-49.

8. Fallatah HI. Noninvasive Biomarkers of Liver Fibrosis: An Overview. Adv Hepatol. 2014; Article ID 357287: 1-15.

9. Qin J, Kilkus J, Dawson G. The hyaluronic acid inhibitor 4-methylumbelliferone is an NSMase2 activator-role of Ceramide in $\mathrm{MU}$ anti-tumor activity. Biochim Biophys Acta. 2016; 1861(2): 7890.

10. Mauro E, Crespo G, Londoño MC, Diaz A, Ruiz P, Sastre $L$, et al. Noninvasive assessment of liver fibrosis and portal hypertension after viral eradication in post-transplant hepatitis C. J Hepatol. 2017; 66(1): S237.

11. Piccinino F, Sagnelli E, Pasquale G, Giusti G. Complications following percutaneous liver biopsy. A multicentre retrospective study on 68,276 biopsies. J Hepatol. 1986; 2(2): 165-173.

12. Qu F, Holloway JL, Esterhai JL, Burdick JA
Mauck RL. Programmed biomolecule delivery to enable and direct cell migration for connective tissue repair. Nat Commun. 2017; 8(1): 1780.

13. Gudowska M, Cylwik B, Chrostek L. The role of serum hyaluronic acid determination in the diagnosis of liver fibrosis. Acta Biochim Pol. 2017; 64(3): 451-57.

14. Erickson M, Stern R. Chain gangs: New aspects of hyaluronan metabolism. Biochem Res Int. 2012; Article ID 893947: 1-9.

15. Nyberg A, Engstrom-Laurent A, Loof L. Serum hyaluronate in primary biliary cirrhosis--a biochemical marker for progressive liver damage. Hepatology. 1988 Jan-Feb; 8(1): 142-6.

16. Abd-Elghanya SM, Ahmed Ibrahem EE, El-Sayed SZ, Mohammed S, Morsy AA. Serum hyaluronic acid as a noninvasive marker of hepatic fibrosis in chronic hepatitis c patients. Al Azhar Assiut Med J. 2016; 14(2): 67-75.

17. Guechot J, Loria A, Serfaty L, Giral P, Giboudeau $J$, Poupon R. Serum hyaluronan as a marker of liver fibrosis in chronic viral hepatitis C: effect of alpha-interferon therapy. J Hepatol. 1995; 22(1): 22-26.

18. Parsian H, Rahimipour A, Nouri $M$, Somi $M H$, Qujeq D. Assessment of liver fibrosis development in chronic hepatitis B patients by serum hyaluronic acid and laminin levels. Acta Clin Croat. 2010; 49(3): 257-65.

AUTHOR AFFILIATION:
Dr. Muhammad Akram
Associate Professor, Department of Biochemistry
SFINHS/SKBZMDC, Shaikh Zayed Postgraduate Medical Institute
Lahore, Punjab-Pakistan.
Dr. Ali Raza Memon (Corresponding Author)
Assistant Professor, Department of Biochemistry
Liaquat University of Medical \& Health Sciences
Jamshoro, Sindh-Pakistan.
Email: ali.bio.lumhs@gmail.com, raza.memon@lumhs.edu.pk
Dr. Pushpa
Assistant Professor, Department of Physiology
Muhammad Medical College Mirpurkhas, Sindh-Pakistan.
Dr. Farman Ullah Farman
Cancer Genetics \& Epigenetics Lab, Department of Biosciences
COMSAT Institute of Information Technology, Islamabad-Pakistan.
Dr. Muhammad Imtiaz Shafiq
Institute of Biochemistry\& Biotechnology
University of the Punjab, Lahore-Pakistan.

